\title{
Physical Internet - a Novel Application Area for Industry 4.0
}

\author{
E. PUSKÁs ${ }^{1}$, G. BoHÁCS ${ }^{2}$ \\ Budapest University of Technology and Economics, Faculty of Transportation Engineering and Vehicle \\ Engineering, Department of Material Handling and Logistics Systems \\ 1eszter.puskas@logisztika.bme.hu \\ 2gabor.bohacs@logisztika.bme.hu
}

Abstract. The Physical Internet (PI or $\pi$ ) is one of the most decisive ideas for future logistics systems. The idea behind it is to implement logistic systems which apply the principles of Internet information flow. Simultaneously technological innovations of Industry 4.0 have also appeared. Our current research deals with the applicability of the tools of Industry 4.0 technology in the PI system. Following the literature review we analyse the individual technological tools that could improve the functioning of PI components. Subsequently we will detail the usability of a specific Industry 4.0 tool and finally determine the future research steps.

\section{Introduction}

Physical Internet (PI) is one of the most dominant trends for future logistics systems. The PI uses the Internet metaphor even though there are fundamental differences between the information and the physical world. In the future logistics system, physical goods are delivered in a way that the internet supplies the data. The goods are managed as standard packets similar to information flow of the Internet, which are handled as data packets. There are several partial solutions and pilot systems for the operation of the theoretical global, open logistics network, but the breakthrough still has to be expected. Parallel to the development of the Physical Internet concept, Industry 4.0 solutions were also improved. The Industry 4.0 system offers a wide variety of technological solutions which are being developed and implemented today. Although there is no clear classification, which tools belong to Industry 4.0, and which are not. In this paper, we are going to present the description of the concept and main solutions of the PI. Next, we are going to look at the technology pillars of Industry 4.0. Finally, following the literature review we examine the individual technological tools that could improve the functioning of PI components. Subsequently we will detail the usability of a specific Industry 4.0 tool and finally determine the future research steps. This paper is part of our teaming project „EPIC” that has received funding from the European Union's Horizon 2020 program.

\section{Introduction of the Physical Internet Concept}

As a result of the globalization and product individualisation of the world, pressure on the performance of logistics systems is increasing. In addition to the increasing demand for unique 
products, the product assortment also grows incredibly. This global market change has a major impact on the operation of the systems which will make the current operation conditions unsustainable. This problem must be addressed in social, economic and environmental terms. Because of the overpollution of the past years and the flow of energy, environmental protection is a constant part of the development directives. The importance of social life and personal health can be justified by the central role of human, since the most systems can now only operate with a lot of manual work and human intervention. It is a global challenge in the world to make it possible to handle the increasing customer demands by the performance of the systems. The Physics Internet concept provides a solution to manage these problems and create a sustainable network. [1]

\subsection{Definition of the Physical Internet}

The foundations of the Physical Internet (PI, $\pi$ ) were formulated by Montreiul in the Physical Internet Foundations. He defined that the concept of PI presents an open, global logistics system that is implemented through physical, digital and operational interconnection. Its main purpose is to achieve such a sustainable system which is able to operate effectively worldwide. The basic idea is based on the operation of the digital world, where we forward our data according to the TCP / IP protocol as in our everyday life in other areas. The way we do not transmit data, but data packages on the Internet, so the Physical Internet plans to store and transmit individual physical goods as a standard package. Customer orders may consist of several packages which are transported by different vehicle and can use routes between the starting point to the end point. Naturally, at the end of the process they are interconnected again. The expected efficiency would be achieved by the optimal operation of the connection system between the elements in the network. The global vision requires the operation within a standard framework, whose foundations, principles and requirements are open to widened circle of logistics network participant. [2] Horst Treiblmaier and co-authors summarized the components of the Physical Internet. [3] The solutions of the PI system are including the optimization of the use of modular containers, transit centres, hubs and vehicles. Additionally, more researchers dealt with the issue of secure data exchange and the development of collaboration and business models. [3]

\subsection{Components of the Physical Internet}

The researchers began to examine the standard delivery units for the standard transportation method of the products. It was agreed that the 20- and 40-foot ISO containers already used in logistics have become the basis of design. This clearly determines the potential dimensions of $\pi$-containers designed for use in the Physical Internet system as defined in article written by Landschützer in 2015. [4] When designing a container, the sustainability goal set in the Physical Internet must also be followed.

In addition to meeting the environmental requirements, it is necessary to keep in mind the expectations to ensure the effective operation of the operational level, which includes easy handling, storage and transport. For this purpose, it is essential to create functions when designing containers, such as interlocking, folding and joining. At operational level, data related to containers, such as product and delivery information, must be guaranteed for day-to-day operation. Depending on the 
level of responsibility, which data is available to the user. The user can only see the unconditional data he needs, which can be human or also a machine in the future. The essence of this box is that each product uses the best possible volume utilization to fit a modular container and represents the goals of the Physical Internet, which is recyclable, environmentally friendly, intelligent and compatible with each other. The main features and capabilities are summarized in Figure 1.

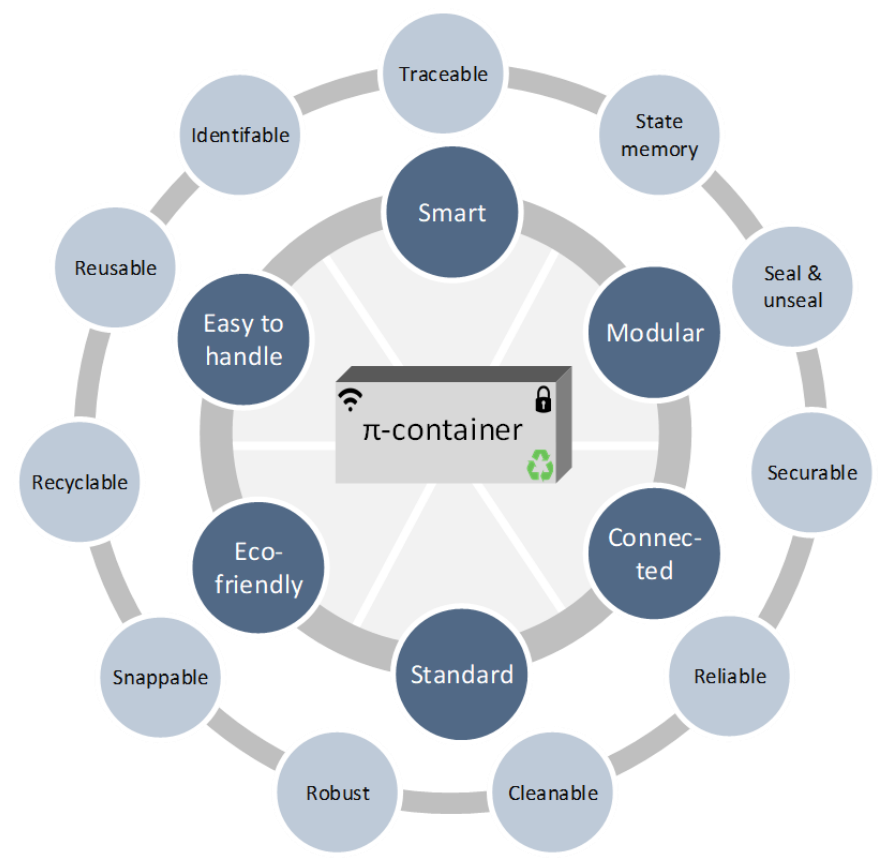

Figure 1. The main features of $\pi$-containers

The basic elements of the global system include open $\pi$-transit centres which can have different traffic modes. These centres offer solutions to better utilize vehicles and improve social welfare while maximizing global efficiency. In the current system, the distance to be taken by drivers is not sustainable. This distance can be reduced by designing these $\pi$-centres. Another problem is that drivers are getting away from home right away. Modularity provided by transit centres allows drivers to switch between trucks. The $\pi$-sorters are important parts of the transfer points that provide the containers with the right truck in the correct sequence and time. When assigning the next task, the system keeps in mind drivers returning home as soon as possible. These centres would use renewable energy sources to protect the environment and autonomous operation of the system would help increase effectiveness. Furthermore, in order to increase flexibility, the shipment within the logistics network would follow the hub and spoke transport strategy.

Vehicles are equipped with $\pi$-containers based on the capacity and the route to the next center, which radically reduces the low utilization of current networks. Distribution centres of PI are accessible to everyone by forming an open network. The objects (workers, containers, vehicles, machines) contained therein are connected to the system.

Montreiul has developed a framework for the operation of the centres, depending on the various transport connections. [5] [6] The operation of open centres is closely linked to the system of sharing vehicles to improve utilization and efficiency. The theory of freight transport implemented in the 
Physical Internet system is extremely innovative, in which trucks and trailers and also the drivers can be combined as a detached resource. The concept is that the trailers arrive at the centres with a truck and trailer, but they could move forward with a completely different driver and a truck. In addition, the contents of the trailer may change according to the destination of the goods. Furtado and Frayre presented a simulation model that demonstrated the positive effects of sharing and modularity. The results show that the delivery tasks implemented in the Physical Internet concept improve the financial, social and environmental impacts. [7]

\section{Technological pillars of Industry 4.0}

Industry 4.0 is an emerging strategy that is intensively used by both old-established and new information and communications technology innovations. It is not based on the used tools and systems, but rather on a way of thinking how people and machines could create a common system. His primary goal was to create future production systems. The approach is constantly evolving, there is no boundary limit that defines where we say a system an Industry 4.0 concept. The presence of Industry 4.0 integration can be determined by deciding whether a function is Industry 4.0 compatible or not. [8] Below we will review the technological tools that are considered as appearance of Industry 4.0. First of all, it was concluded that there is no unambiguous classification of technologies for the inclusion into Industry 4.0. In the past, several researchers reviewed the Industry 4.0 technologies. In our article we overview three of these researches.

Bohács et al. [8] identified six Industry 4.0 key components. Existing logistic networks become Industry 4.0 system using cyber-physical connectivity. To ensure real-time information flow and tracking, the components can communicate each other through the cloud system. This is accomplished by other tools such as a barcode system or a Wi-Fi localization. There is a two-way decision making between the human and machine elements. In order for a person to be able to interfere in processes, the machine must provide all the necessary information. The intervention can be carried out in the simplest way by creating a virtual reality, which is a virtual duplication of the controlled system. The idea of flexibility created by virtual reality is extended to real-world physical systems, from which the implementation of modular material handling systems is required from the logistics side. The power of modularity can be strengthened by decentralized decision-making. [8]

Saturno and co-authors present 9 technologies as fundamentals to support the industrial production of the future. While the previous grouping looked at the main forms of appearance from the side of functions, this article describes the technology pillar of Industry 4.0, shown in Figure 2. In their opinion, the technologies must meet the requirements of the functions of Industry 4.0. Based on this, core pillars include technologies such as Mobile Technology, 3D Printing and RFID technologies, as well as functions such as Cyber security, Cloud Computing, M2M, Advanced Robotics, Big Data / Analytics, IoT and Cognitive Computing. [9] 


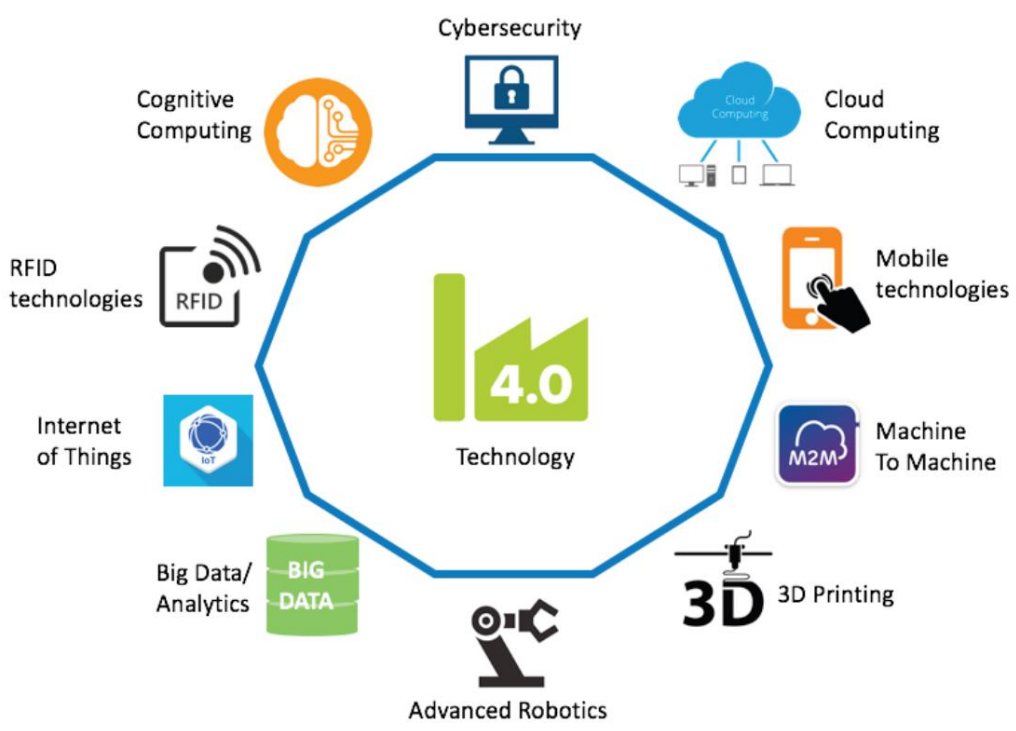

Figure 2. Technological pillars of Industry 4.0 [9]

The grouping in the third article represents a section of the previous two. Vaidya et al. say that there are nine main drivers of Industry 4.0 that help transform the manufacturing process into a fully integrated, automated and optimized one. As in the other articles, they also included Big Data and analytics, the IoT, cyber security and cyber physical systems (CPS), the Cloud and Augmented Reality as main pillars. In their opinion, the tools and functions required in Industry 4.0 are the autonomous robots, simulation, system integration and additive manufacturing. [10]

There are some identical elements that are important to all the presented articles, but there are different ideas as well. In classification, the number of components in one pillar is not necessarily the same. For example, Cyber Security and Cyber Physical systems are considered to be a common pillar, some say it is a separate element. In this article, we do not intend to create a new grouping. The classification created by the different principles are shown in Figure 3. By creating a comprehensive picture, we can analyse which tools and features can help increase the efficiency of the systems created by the Physical Internet.

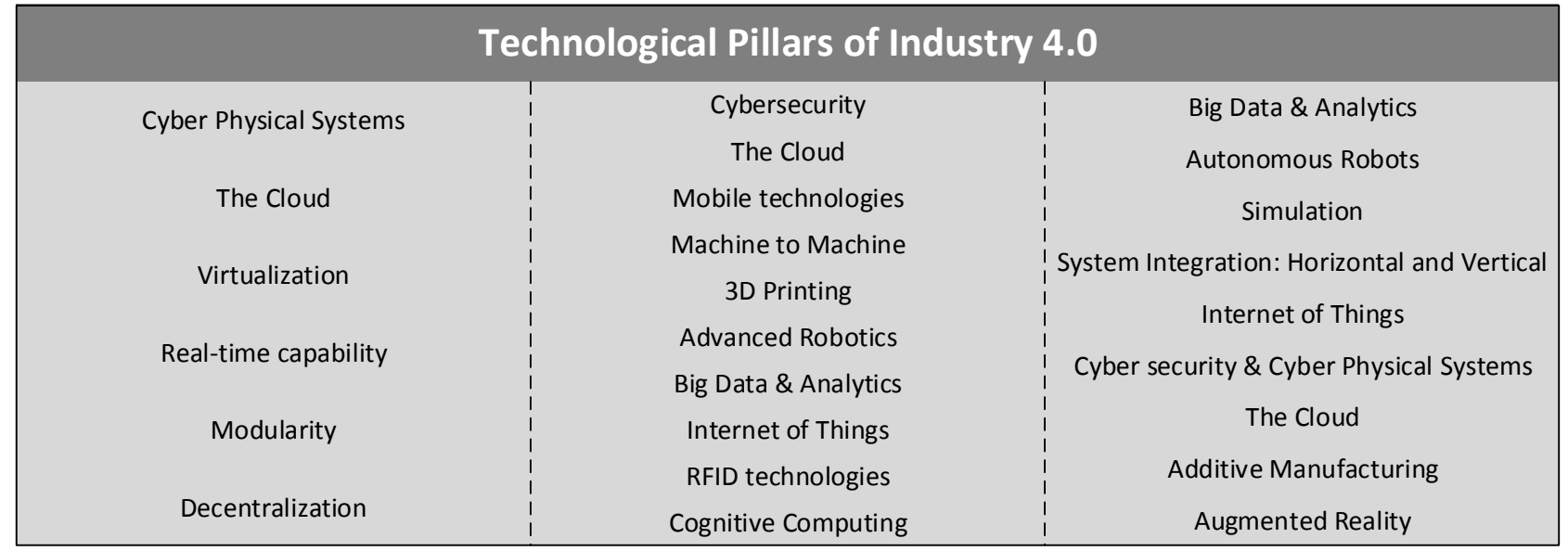

Figure 3. Main pillars of Industry 4.0 


\section{Applicability of I4.0 technologies for the improvement of the PI components}

In this section, we analyse which industry 4.0 tools and function support the components of Physical Internet. Among the devices since we did not aim to create a new classification, we consider all appearance in the three articles. In our article, the technology pillars are individually listed to examine the applicability, so we do not combine Cyber security with Cyber Physical System (CPS) elements. The components of the Physical Internet are based on the article of Horst Treiblmaier. [3] The parts of the PI system are the $\pi$-container, $\pi$-hub, track and trace solutions, smart objects, $\pi$-sorters, hub-andspoke transport, unified framework, Open Global Logistics Web, open monitoring system and webbed reliability. [3] Table 1 shows which Industry 4.0 technology device can be used for components appearing in the Physical Internet system. If it is possible to define a connection between them, the table denotes an "x" sign.

The density of "X" shows which Industry 4.0 devices are of the outstanding importance for the Physical Internet. It can be noted that the technical elements and components defined by the two trends have many common intersections, but there are also some technological tools that are not relevant to PI, such as 3D printing. In the following, we discuss this applicability from the point of view of the components of Physical Internet.

Table 1. Industry 4.0 devices that affect PI components

\begin{tabular}{|c|c|c|c|c|c|c|c|c|c|c|}
\hline INDUSTRY 4.0 / PHYSICAL INTERNET & $\begin{array}{c}\pi- \\
\text { container }\end{array}$ & $\pi$ - hub & $\begin{array}{l}\text { Track \& } \\
\text { Trace } \\
\text { solution }\end{array}$ & $\begin{array}{c}\text { Smart } \\
\text { objects }\end{array}$ & $\pi$ - sorter & $\begin{array}{l}\text { Hub-and- } \\
\text { spoke } \\
\text { transport }\end{array}$ & $\begin{array}{c}\text { Unified } \\
\text { framework }\end{array}$ & $\begin{array}{c}\text { Open Global } \\
\text { Logistics } \\
\text { Web }\end{array}$ & $\begin{array}{c}\text { Open } \\
\text { monitoring } \\
\text { system }\end{array}$ & $\begin{array}{l}\text { Webbed } \\
\text { reliability }\end{array}$ \\
\hline Cyber Physical Systems & & $\mathrm{x}$ & & & & & & $\mathrm{x}$ & & \\
\hline Cyber securty & & & & & & & & & & $\mathrm{x}$ \\
\hline The Cloud & & $x$ & $x$ & $x$ & & & $\mathrm{x}$ & $x$ & $x$ & \\
\hline Mobile technologies & $x$ & & $x$ & $\mathrm{x}$ & & & & $\mathrm{x}$ & $x$ & \\
\hline Machine to Machine & & $x$ & $x$ & & & $x$ & & $x$ & & \\
\hline 3D Printing & & & & & & & & & & \\
\hline Advanced Robotics & & $x$ & & & $\mathrm{x}$ & & & & & \\
\hline Autonomous Robots & & $x$ & & & $x$ & & & & & \\
\hline Big Data \& Analytics & & $x$ & $x$ & & $x$ & & $x$ & $x$ & & \\
\hline Internet of Things & $\mathrm{x}$ & & & $\mathrm{x}$ & $\mathrm{x}$ & & & & & \\
\hline RFID technologies & $x$ & $x$ & & $x$ & $x$ & & & & & \\
\hline Cognitive Computing & & & $\mathrm{x}$ & & $\mathrm{x}$ & & & & & \\
\hline Virtualization & & $\mathrm{x}$ & & & $\mathrm{x}$ & & & & $x$ & \\
\hline Real-time capability & & $\mathrm{x}$ & $\mathrm{x}$ & & & & & & $x$ & \\
\hline Modularity & $\mathrm{x}$ & & & $\mathrm{x}$ & $x$ & & & $\mathrm{x}$ & & \\
\hline Decentralization & & $\mathrm{x}$ & $\mathrm{x}$ & $\mathrm{x}$ & $\mathrm{x}$ & & & $\mathrm{x}$ & & \\
\hline Simulation & & $x$ & $x$ & & $x$ & $x$ & & $\mathrm{x}$ & & \\
\hline System Integration (Horizontal and Vertical) & & $\mathrm{x}$ & $\mathrm{x}$ & & & $\mathrm{x}$ & & $\mathrm{x}$ & & \\
\hline Additive Manufacturing & $x$ & & & & & & & & & \\
\hline Augmented Reality & & $x$ & & & & & & & & \\
\hline
\end{tabular}

One of the most important constituents of the PI system is the $\pi$ container, which would work in the future system with smart tools. This goal is promoted by Industry 4.0 technologies such as mobile technology, IoT and RFID technologies. Containers with RFID tags can be easily identified anywhere in the system and also contain the necessary information. Without this, it is almost inconceivable that a $\pi$-container is integrated into the open logistics network of the future. The objects in the PI system are part of the IoT world thus additive production is highly useful in the production of containers. 
The dominant part of the open logistics network are $\pi$-hubs, which provide the basis of the system with fixed, but accessible points for any $\pi$-certified users. These transfer points are loaded with several features, such as guaranteed parking for trucks, loading and unloading products or $\pi$-containers, cargo carrier replacement, or even a turning point for drivers, after which their track can go home. Due to its multifunctional attribution, almost every technology can directly or indirectly advance the innovative development of the center. Considering the complexity of the system, it is important to mention the applicability of the following Industry 4.0 technology devices for $\pi$-hubs: CPS systems in which elements can systematically think and communicate via a data structure similar to the Internet, or closely related Big Data \& Analytics, which is managed and uses a large amount of data. [11] Furthermore, the advantages of cloud, M2M, virtualization, real-time capability, decentralization as a system functionality are of great benefit to the $\pi$-hubs. When operation starts in a new center, training can be supported by augmented reality (AR) as an Industry 4.0 tool. Finally, we would mention the importance of applying simulations to optimize the design and operation of the transfer points.

To ensure that all objects from $\pi$-containers to carriers flow smoothly in the Physical Internet network, it is necessary to have track and trace system. Track and trace is the process of identifying the past and the current locations. Each single good is encapsulated in modular boxes and these are in different carriers. The tracking of each single item is obtained by tracking dynamic aggregation of boxes, that travels from one node to another. For this component, it is also necessary to mention elements that provide system development such as cloud, Big Data \& analytics, decentralization and system integration. Mobile devices are an essential component of trucks, which makes it easier for drivers to work and become traceable. Simulation and cognitive computing are a useful function for both operational and strategic planning, which is based on artificial intelligence and can be used for everyday decision.

A smart tag is attached to each container. It contributes to ensuring container identification, monitoring, traceability and security through the Physical Internet. Smart objects are communicating and interacting with each other and they are capable of independent decision making. To make smart objects intelligent, we can clearly associate Industry 4.0 solutions. For the purposes of this requirement PI and Industry 4.0 can be parallelized, as both are designed to promote an intelligent, smart world. Objects here can mean products, infrastructure items, material handling machines or even delivery vehicles. For this reason, connecting and communicating of elements and their autonomy are ensured by the following Industry 4.0 tools: cloud, mobile technologies, IoT, RFID technology, modularity and decentralization.

An important element of the transit points are the $\pi$-sorters. Their task is to get the $\pi$-containers to the right vehicle in the right time and sequence. Industry 4.0 system features are also shown here as Big Data \& analytics, IoT, cognitive computing, virtualization, decentralization and simulation. Because the sorters usually move the containers the applicability of RFID technology is really important. In addition to the previous elements, advanced robotics and autonomous robots such as Industry 4.0 can be used for $\pi$-sorting. Following a given instruction, these tools can be used for handling and transport tasks. 
Freight transportation is now dominated by end-to-end transportation and objects are moved through networks dedicated to specific transportation business. Because of this, the trucks are often already half empty at departure which means larger environmental pollution. The future logistics network imagined in the Physical Internet would work on the hub-and-spoke transport system to make the system more flexible. The operation of such a system is improved by horizontal and vertical integration and the simulation defined as Industry 4.0 tool for the appropriate use of resources and organizational optimization. The whole system was determined Physical Internet is an open, global logistics network. This approach is supported by Industry 4.0 technologies that improve the overall system, such as CPS, Cloud, M2M, Big Data \& analytics, modularity, decentralization, simulation.

PI components include requirements that ensure the operation of the system at a global level. This includes the Unified Framework, with cloud and Big Data tools providing the necessary information and conditions. Future logistics network must be equipped with an open monitoring system to ensure feedback, communication and control. The cloud as an Industry 4.0 technology tool may also be considered as a condition for its operation. This way we can ensure that data can be accessed from anywhere and at any time. Nowadays it is a basic requirement that such a control function be available on mobile in real time. Finally, the creation of secure security in all areas, which clearly affects the applied IT technologies in a digitized world.

\section{Application of a selected technology in the PI system}

Many researchers agree that current logistic networks can be defined as a complex system. [12] [13] In the future the Physical Internet system will also have to face this complexity. Companies are increasingly expanding their relationships, where physical distance is no longer a limit. The expansion of the network is true for both supplier and customer relationships, because it provides opportunities for anyone to find new partners and establish business relationships by using the Internet. This makes it possible to increase the network nodes, in addition to the interaction between the centres is more frequent and fragmented. Customers increasingly want to quickly receive the product ordered, regardless of distance. To design, operate, and develop such a complex system, we think that simulation is highly important.

The behaviour of a compound system cannot be predicted solely by examining the behaviour of individual parts. [14] Thus, we need a model of the entire system. As simulation used extensively by Industry 4.0, we suggest this has to be the first approach to improve the components of Physical Internet.

In the Physical Internet system, for example, hub-and-spoke delivery can be further enhanced by simulation. Within this hub-and-spoke transport, the $\pi$-hubs can be defined, and simulations also can be applied to the design, optimization and development of these separate system. The above describes a complex system, which is determined by the individual elements in it, such as $\pi$-hubs, vehicles, machines and devices and communication and connection between them. The internal processes of $\pi-$ hubs have been analysed in several articles by Montreiul, considering various transport connections. [5] Since we have fixed the nodes and the logic that connects them, the simulation tool provides us with the solution to support our design and testing. 


\section{Conclusion and Future Work}

The Physical Internet is a new concept that is primarily intended to make the operation of the global logistics network economically, environmentally and socially viable and sustainable throughout the world. This is one of the most decisive ideas for the future system, for which many partial solutions have been developed. Many researchers have investigated the components and functions of the system, such as the design of $\pi$-containers or $\pi$-hubs. Parallel with the Physical Internet technological innovations of Industry 4.0 have also appeared. Industry 4.0 tools have many different classifications, it was concluded that there is no uniformly accepted classification. In this article, we compared the views of three different sources, which are defined as Industry 4.0 pillar in different groupings and different elements.

In the second part of this article we have analysed which Industry 4.0 technology tool can be used for the Physical Internet component. The result is summarized in Table 2, which includes all defined Industry 4.0 tools and Physical Internet components. It can be seen that the most commonly used tools include cloud, mobile technology, Big Data \& analytics, decentralization and simulation. In the following chapter we discussed the importance and the possibility of using the simulation function. As simulation used extensively by Industry 4.0, in our opinion this has to be the first approach to improve the components of Physical Internet.

The next step of the research is to find a novel theoretical model that can be used for the Physical Internet based logistics network. When constructing the model, it is necessary to examine how each $\pi$ hub fits into the hub and spoke transport structure, meaning how the transport, storage and movement between and within the centres will be realized. After developing the theoretical model, it is required to optimize each module of PI. It is important to use the simulation to validate the model of the complex system, then we can analyse the modifications due to different impacts.

\section{References}

[1] B. Montreuil (2011) Toward a Physical Internet: meeting the global logistics sustainability grand challenge. Logistics Research. pp. 71-87.

[2] B. Montreuil - R. D. Meller - E. Ballot (2012) Physical Internet Foundations, IFAC - Information Control Problems in Manufacturing. Bucharest, Romania.

[3] H. Treiblmaier - K. Mirkovski - P. B. Lowry (2016) Conceptualizing the Physical Internet: Literature Review, Implications and Directions for Future Research, 11th CSCMP Annual European Research Seminar, Vienna, Austria.

[4] C. Landschützer - F. Ehrentraut - D. Jodin (2015) Containers for the Physical Internet: requirements and engineering design related to FMCG logistics. Logistics Research.

[5] B. Montreuil - R. D. Meller - C. Thivierge - Z. Montreuil (2012) Functional Design of Physical Internet Facilities: A Road-Based Crossdocking hub. Progress in Material Handling Research.

[6] B. Montreuil - R. D. Meller - C. Thivierge - Z. Montreuil (2012) Functional Design of Physical Internet Facilities: A Road-Rail Hub. Progress in Material Handling Research. 
[7] P. Furtado - J.-M. Frayret (2014) Impact of resource sharing of freight transportation. 1st International Pysical Internet Conference, Québec City, Canada.

[8] G. Bohács - A. Rinkács - R. Glawar - P. Hold (2015) Az Ipar 4.0 alkalmazása az üzemi logisztikában. Gépgyártás. pp. 46-50.

[9] M. Saturno - F. Deschamps - V. M. Pertel (2017) Proposal of an automation solutions architecture for Industry 4.0. 24th International Conference on Production Research, Poznan, Poland.

[10] S. Vaidya - P. Ambad - S. Bhosle (2018) Industry 4.0 - A Glimpse, Procedia Manufacturing. pp. 233-238

[11] E. Hofmann - M. Rüsch (2017) Industry 4.0 and the current status as well as future prospects on logistics. Computer in Industry. pp. 23-34.

[12] S. Pathak - A. Nair - J. M. Day - M. M. Kristal (2007) Complexits and Adaptivity in Supply Networks: Building Supply Network Theory Using a Complex Adaptive Systems Perspective. Decisions Sciences. pp. 547-580.

[13] A. Surana - S. Kumara - M. Greaves - U. N. Raghavan (2007) Supply-chain networks: a complex adaptive systems perspective. International Journal of Production Research. pp. 4235-4265.

[14] P. Cilliers (2000) Rules and Complex System. Emergence: Complexity \& Organization. pp. 40-50.

[15] D. Hakimi - B. Montreuil - R. Sarraj - E. Ballot - S. Pan (2012) Simulating a physical internet enabled mobility web: the case of mass distribution in France. 9th International Conference of Modeling, Optimization and Simulation, Bordeaux, France. 